\title{
"Why do I have to learn this?" A case study on students' experiences of the relevance of mathematical modelling activities
}

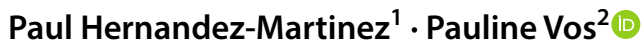

Accepted: 12 December 2017 / Published online: 22 December 2017

(c) The Author(s) 2017. This article is an open access publication

\begin{abstract}
In this paper we explore how students can experience the relevance of mathematical modelling activities. In the literature we found that relevance is a connection among several issues (relevance of what? to whom? according to whom? and to what end?). We framed this concept in terms of Cultural-Historical Activity Theory (CHAT), a theory for analysing how individuals engage in activities within social environments. We designed modelling activities within a mathematics course for engineering students: there were ample mathematical modelling tasks, a guest lecture by an employee from an engine company who used mathematical modelling in his job, and a group work modelling assessment with a presentation to the whole group. After the course, we interviewed ten students with a wide range of final grades in the course. We analysed the interview data in light of the theoretical framing of the concept of relevance. Our analysis showed that, generally, students experienced the modelling activities as relevant, and that they imagined themselves working in professional practices for which mathematics is relevant. However, doing mathematics was also judged as being relevant only to obtain grades, leave school and enter professions for which mathematics might not be needed. We offer recommendations for making mathematics education more relevant to more students.
\end{abstract}

Keywords Cultural-Historical Activity Theory · (Mathematics in) engineering education · Future professional practices . Mathematical modelling education $\cdot$ Relevance (of mathematics) $\cdot$ Socio-cultural theory

\section{Introduction}

\subsection{Rationale for the study}

If we ask why mathematics is relevant as content to be taught in schools, "one of the reasons which is frequently given is that mathematics is 'useful'; it is clear, too, that this usefulness is in some way seen to be of a different kind from that of many other subjects in the curriculum" (Cockroft 1982, p. 1). There are a variety of reasons given for the teaching of mathematics, such as that it is part of our culture, it teaches students to think logically, and so forth (see Ernest 2005; Heymann 2003). However, in the curriculum documents of many countries, the usefulness of mathematics

Pauline Vos

pauline.vos@uia.no

1 Mathematics Education Centre, Schofield Building, Loughborough University, Loughborough LE11 3TU, UK

2 University of Agder, Gimlemoen 25, PBoks 422, 4604 Kristiansand, Norway in our society-for everyday activities, as the basis of other scientific disciplines, as an effective tool for thinking and communicating and as essential tool in many professions-is presented as primary justification for including it into basic education of all. The usefulness of mathematics is said to 'give relevance' to mathematics. In the ensuing pages we will explore this further: what are the connections between the concepts of usefulness of mathematics and its relevance to students? Our rationale is that many students do not experience mathematics as relevant. For example Matthews and Pepper (2005) report of students dropping the subject, because "they found mathematics to be a dull subject and they could not see the use of mathematics in their future life, for their course or career plans; instead other subjects were deemed to hold more importance to them" (p. 45). Onion (2004) found that the majority of 14-16 year olds "thought that the mathematics they are taught is useful only in mathematics lessons and for exams. They could not see the relevance of it to their current or future lives outside school" (p. 191). Also, Brown et al. (2008) report of 16-year old students saying: "I do not think it [mathematics] will take 
me to where I want to be in life", or "who needs to know trigonometry in everyday life?" There are many students in mathematics classrooms asking the question: "Why do I have to learn this?" The standard teacher's answer "because it will be useful later" silences the question temporarily but this is not a satisfying answer as it does not explain how, why, where and what mathematics will be relevant for a particular student.

\subsection{The relevance paradox}

On the frequently posed question in mathematics classrooms, "why do I have to learn this?", Wedege (2007) pointed to an important distinction. She did research on adults learning mathematics, and distinguished between the questions "why do we have to learn this?" and "why do $\underline{I}$ have to learn this?" The first question is at the systems level and asks for general, objective reasons, such as labour markets needing people with mathematical skills. For societyat-large, it is relevant that future generations learn certain topics of mathematics, and this justifies their inclusion in general curricula. The second question is at the individual level and asks for subjective reasons: why do certain people need certain mathematical skills, and how can I know whether I will be among these? This addresses students' experiences and expectations. The difference between the two perspectives is eloquently expressed by Niss (1994) in his relevance paradox. He suggested the following:

- The objective relevance of mathematics in society contrasts with its subjective irrelevance as perceived by many students and even by people who are supposed to know the role of mathematics in society.

- The function of mathematics in society contrasts with mathematics in the classroom.

- Students experience a lack of connection (subjective irrelevance).

He explained that large groups of students suffer from a paradoxical dilemma at the personal level and one of them said: "Mathematics is useless to me, but at the same time I know that I am useless without mathematics" (p. 377).

\subsection{Relevance as aspect in the affective domain}

Students' perception of the relevance of mathematics is part of their beliefs about mathematics (McLeod 1992), also known as mathematical world views or conceptions of mathematics. Grigutsch et al. (1998, cited in Liebendörfer and Schukajlow 2016) distinguishes between four belief aspects: beliefs about the processes of mathematics, beliefs about its applications, beliefs about schema, and beliefs about formalism. The second category, beliefs about applications, highlights the practical use of mathematics in everyday tasks and problems, for jobs and for society. As beliefs are subjective perceptions, so are students' experiences of the relevance of mathematics.

Students' experience of the relevance of mathematics (or the lack thereof) is connected to their motivation to learn. For instance, Newby (1991) found a positive correlation between relevance strategies by teachers (i.e. making the content relevant) and the time that students spent on a task. These instructional relevance strategies emphasised the discussion of the question "why do I have to learn this?" The important role of a teacher/trainer in conveying relevance is also confirmed in Roszkowski and Soven (2010), who suggested that "since usefulness and learning are related, trainers need to find ways of demonstrating the subject matter's relevance to the trainee" (p. 82). Numerous other studies on relevance from the general education literature, in particular in adult learning and corporate training, relate relevance to motivation and to usefulness. For example, in their seminal article, Zempke and Zempke (1981) say that adults do not want to learn for the sake of learning but are motivated to learn "because they have a use for the knowledge or skill" (p. 46).

Thus, relevance is related to a motivation to learn and, in particular, to the perception of usefulness of what is being learnt. So, in the present paper we distinguish between usefulness and relevance as follows: usefulness is a property of the topic being learnt (e.g. mathematics is useful for solving problems), while relevance is a connection between the topic being learnt, its usefulness and a learner (e.g. trigonometry is relevant for a student if he can use it later), and additionally, relevance can be mediated by someone else, for example a teacher. In the next section, we will expand this subjectiveness of relevance. Of course, other people can find a certain topic to be relevant for the students to learn (e.g. a teacher or a curriculum designer), but in this article we will take a student-centred perspective: we want to study relevance from the students' point of view, and consider how relevance influences students' motivation and why one student 'sees' the relevance, while another one does not.

The relationship between learning about the relevance of mathematics and motivation is not straightforward. This was demonstrated by Loch and Lamborn (2016), who carried out a project with first-year undergraduate engineering students. To convey the relevance of mathematics, videos were produced showing how mathematics is used in engineering. They found that some students were engaged by the videos, but others were intimidated by the complexity of the mathematics displayed. Thus, showing relevance can be counterproductive to motivation (e.g., a student thinking that they are not good enough to do that level of mathematics). This was also noted by Kember et al. (2008) who showed how the material taught could motivate students by demonstrating its 
relevance to a future profession, but students also became demotivated if that specific profession was not part of their expected career. In a similar vein, Black et al. (2010) present the case study of Lee, a student who was taking a pre-university mathematics course designed to highlight the application of mathematics to the real world. However, this student did not find this relevant, as he expressed as follows (p. 64):

Int: So you don't find the context interesting or relevant?

Lee: No, it's not relevant to me. I don't need to know that. [..] I don't need to know how to do trigonometry, in everyday use. So, I don't see that as real-life context.

This shows that what a teacher may perceive as relevant may fail to show the relevance of mathematics to students.

\subsection{Relevance of mathematics mediated by mathematical modelling activities}

A mathematics teacher can show and tell about the usefulness of mathematics, while keeping the curriculum focus unchanged on traditional, pure mathematics with few applications. However, instead of a teacher conveying relevance, in many curriculum documents there are recommendations that students should experience the usefulness of mathematics through mathematical modelling activities, in which students themselves use mathematics for solving real-life problems (Blum 2015; Stillman et al. 2013b). This aim can be related to a pragmatic perspective on mathematical modelling (Kaiser 2014), which puts utilitarian aims for mathematical modelling activities in classrooms to the fore. This perspective emphasises that mathematics is a tool to solve non-mathematical, real life problems. We implemented this perspective in our study by asking students, among other things, to solve a complex workplace-related problem in groups; this activity covered several course weeks (further details are given in the Sect. 3). This pragmatic perspective is also known as 'mathematical modelling as content' as opposed to using modelling activities following the scientific-humanitarian perspective, also indicated by 'modelling as a vehicle' to learn mathematics (Julie and Mudaly 2007). In the latter perspective modelling activities are used to introduce abstract mathematical concepts or to foster motivation towards (pure) mathematics.

There is ample evidence that students are motivated when they engage in mathematical modelling activities (e.g. Bonotto 2010; Cardella 2010; Kaiser et al. 2011; Maaß 2010; Schukajlow et al. 2012; Stillman et al. 2013a), although this effect is task-specific, context-specific, and short-term. Also, motivation in modelling activities does not automatically translate into motivation for mathematics at large. We note that in most studies on modelling and motivation, it remains unclear whether students' motivation is related to experiences of relevance, or to other aspects. These can be, for example, enjoyment or interest, which are aspects of the affective domain that differ from experiencing relevance. For example, students can find the social component of group work (a frequently used practice in mathematical modelling education) as enjoyable, even if there is no experience of relevance. We want to further distinguish between interest and relevance. Rellensmann and Schukajlow (2016) define interest as a psychological state, which describes a relationship between a person and an object; for an object to be interesting, there is no need for a usefulnessorientation. So, when Julie and Holtman (2008) asked students in grades $8-10$ what contexts they would prefer to deal with in mathematical activities, they asked for their interest, because they did not ask students for any future use. Thus, some students can find a task about a May-pole for a traditional dance interesting (as a folkloric or historic phenomenon), while simultaneously perceiving it as irrelevant (as an activity never ever to engage in). Similarly, these researchers found that students considered ethnic art to be interesting, but not relevant.

As said above, mathematical modelling may motivate students, but it remains a question how they experience the relevance of such activities. Therefore, we set up a study, in which students engaged in mathematical modelling activities. The research question was as follows: How do students experience the relevance of mathematical modelling activities after having completed a course with mathematical modelling elements?

\section{Theoretical frame for the relevance of mathematical activities}

\subsection{Relevance as a connection}

In the previous section, we already stated that relevance is a connection among an object (task or topic being learnt in mathematics or mathematical modelling), its usefulness and a person. This builds on a definition by Nyabanyaba (1999), who suggested three key issues in the study of relevance: relevance of what, relevance to whom, and relevance to what end. The first issue states that relevance relates to an object (task activities, mathematics-at-large), the second issue states that relevance is related to a person (a student), and the third issue states that relevance requires a goal orientation. Thus, when mathematical modelling activities deal with contexts beyond the classroom, but the student does not relate these activities to a goal (e.g. a future profession), he or she will not easily perceive the modelling activity as relevant.

A different definition of relevance was provided by Ernest (2004). He defined relevance as a ternary relation between 
three things ( $R, P, G)$. R is a situation, an activity or an object to which relevance is ascribed. $\mathrm{P}$ is a person or group of people who ascribes relevance to $R$. And $G$ is a goal which embodies the values of $\mathrm{P}$ in this instance. Thus, object $\mathrm{R}$ is relevant when considered so by the person $\mathrm{P}$ in achieving the goal G. Comparing the formulations of Nyabanyaba (1999) and Ernest (2004) we see overlaps: R relates to the question: relevance of what? G relates to the question: relevance to what end? However, Ernest (2004) includes P, the person ascribing relevance. This issue can be phrased in the question format of Nyabanyaba (1999) as follows: relevance according to whom? On the other hand, Nyabanyaba asks a question that Ernest (2004) does not include: relevance to whom? We consider this issue as important, because it addresses Wedege's (2007) distinction between the relevance for me and the relevance for us.

Jablonka (2007) also frames the concept of relevance in a question format, asking: relevant to whom and for what purposes? Her questions are included in the above formulations, whereby the second question (for what purposes?) can be equated to Nyabanyaba's question: relevant to what end? So, based on the work of Nyabanyaba (1999), Ernest (2004) and Jablonka (2007), we define relevance as a connection of four issues:

Relevance of what?

Relevance to whom?

Relevance according to whom?

Relevance to what end?

In focusing on these key issues regarding students' perspective of relevance-in particular the goal-directedness asked by the question "relevance to what end?"-we need to perceive students as socially participating in environments: as students they are in an educational environment, but they also have their peers, families, and their future professional environments. To capture the student within these environments, we opted for a framework that was created to analyse the complexity of human activities: Cultural-historical activity theory (CHAT). We make use of second generation CHAT, but we start by shortly explaining its parentage.

\subsection{Introducing cultural-historical activity theory}

The first generation of CHAT was developed by the Russian psychologist Lev Vygotsky (1896-1934) who criticised the limitations of the psychological research of his time, in which a person and his/her mind were studied in isolation from the person's activities. Therefore, he made a person's activity to be the unit of analysis, whereby an activity is framed as consisting of the person (subject), the thing being done (the object of the activity), and the tools used (e.g., language, gestures, physical objects, etc.). An example of such a triad is a research biologist (subject) studying a bird population (object) using mathematical models and computer simulations (tools). Mathematics can be seen as a tool, but it can also be part of the object (e.g., learning mathematics). According to Vygotsky, the biologist's thinking is mediated by the tools used. For example, the mathematical models allow the researcher to run future scenarios, and these enable her to think in probabilistic and dynamic terms. If she did research by merely observing, her reasoning would typically be more descriptive and static.

The second generation of CHAT gives a social embedding to the first generation. Again, a subject engages in an objectoriented, tool-mediated activity, but this happens within a community, which has certain rules and within which there is a division of labour (Engeström 1999). These six components together frame an activity system (see Fig. 1).

To illustrate the difference between first and second generation CHAT, we use again the research activity of a biologist: she can do this to advance her career by publishing articles in prestigious journals. However, she also can do her work within an environmental movement concerned with the variety of species. Depending on the different communities, the biologist will have a different motivation (object), and be subjected to different rules of engagement, roles (division of labour), and so forth. Furthermore, contradictions might occur between the motivation to publish academic articles and at the same time being part of an altruist environmental movement. This perspective makes the activity system, including the social environment, to be the unit of analysis. We consider second generation CHAT to be useful for studying students' experience of the relevance of mathematics, because within activity systems there are always multiple points of view, traditions, interests and contradictions that interact and shape the activity in different ways.

\subsection{Framing relevance within CHAT}

To situate the relevance of mathematics and mathematical modelling, we consider reasons for a subject's engagement in an activity, indicated as motivation. Wells (2011) makes a helpful distinction between a motive of an activity and a

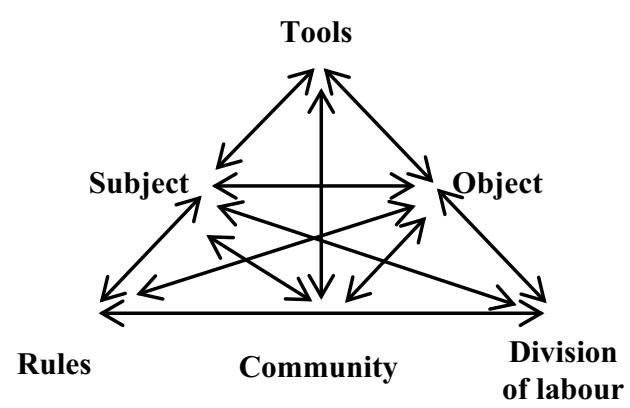

Fig. 1 The structure of an activity system (Engeström 1987) 
motivation. The first, the motive, is at the collective level (for the community); the second, the motivation, is at the individual level (for the subject). Wells (2011) writes as follows:

Motives are what drive activity systems, independently of the specific individuals who enact the necessary roles on any particular occasion. On the other hand, motivation is individual; it is the individuals' need to achieve personal well-being through participation that engages them in the activity on a particular occasion. (p. 91).

For example, a student working on mathematical tasks can have the motivation to pass the examination, whereas the motive of the community in the educational institute is to prepare students for life after school. In fact, Niss' (1994) relevance paradox is about the difference between motives and motivations, and expresses the tensions between these. As he and others observed, the subject's motivations can align with the community's motive, but there will be tensions when this is not the case.

So, how can we analyse the relevance of mathematical activities within a CHAT perspective? As earlier said, we contend that relevance is a connection located in an activity system between the subject and other elements of that activity system. The different elements that form an activity have certain characteristics or properties that interact, and that can add motives and motivation to the activity. This gives us the following points for analysis:

- "Relevance according to whom?" is analysed as relevance as a subjective perception of a person within or outside the activity system. It can be the subject (the student), a member of the community (e.g., a teacher or a potential employer). In the study described in this paper, we limit ourselves to the students' perspective, but future studies may well consider analysing the relevance of classroom activities from the perspective of future employers.

- "Relevance of what?" is analysed as relevance of an activity. In the study described in this paper, we limit the activity to doing mathematical or mathematical modelling tasks, considering that the activity is tool-mediated and set within a community with rules and a division of labour.

- "Relevance to whom?" is analysed as relevance to the subject of the activity, in this case the students, considering that he/she undertakes a tool-mediated activity set within a community.

- "Relevance to what end?" is analysed as relevant to a motive (of the community) or motivation (of the subject). This goal orientation relates, on the one hand, to the social environment, that is: the environment while learning, in particular the role of the teacher or the school, but also to a future, imagined professional environment.
On the other hand, the goal-orientation is also related to usefulness and value (use and exchange).

With this CHAT-based framing, we study how students experienced the relevance of mathematical modelling activities, which they undertook in a course with mathematical modelling elements.

\section{Methods}

We carried out an empirical study within a 12-week, undergraduate mathematics course for second year students in engineering at an English university. This course provided a good case to study students' experience of relevance of modelling activities, for two reasons. First, within engineering degrees, mathematics is vital for many different engineering branches and many different job profiles (Alpers et al. 2013). This could make mathematical activities potentially relevant to students. Second, in this particular course, there were key elements pertaining to mathematical modelling designed to add relevance. Although these key elements were added to the course, it also had to abide by institutional requirements (e.g., a syllabus had to be delivered in weekly lectures and tutorials). This meant that the instructional approach to mathematics and modelling was a mixing approach (Kaiser 2014), whereby there is strong integration of mathematics and modelling but the mathematics used in the modelling problems is more or less given from the outset. The key elements that were added aligned with modelling competencies as described in the literature (e.g., Galbraith et al. 2007; Kaiser 2007; Maaß 2006).

First, each week students were given realistic modelling problems to solve in groups and they had to discuss these problems and come up with a mathematical model for solving the problems using the techniques studied in the lectures. Students reported orally or in writing their solutions and the lecturer would give them feedback. The tasks consisted of problems from engineering, such as modelling a slip casting process with a first order ordinary differential equation, or how to build a fixed-volume aquarium with the minimum possible cost for materials using techniques of multivariable calculus. The task contexts were selected to show the usefulness of mathematics to engineering. The tasks required cognitive modelling competencies, such as understanding a situation, mathematising it, working mathematically, interpreting the mathematical solution, and so forth.

Second, during week 4 (at $1 / 3$ of the course), a guest speaker from a well-known British car and machine manufacturer was invited to give a motivational talk about using mathematics in the workplace; he talked about the use of regression and other statistical methods in his work. This related to one of the topics in the course: functions of several 
variables and the method of least squares. Such an invited talk aligns with the aim of developing conceptions of modelling, also known as meta-knowledge about modelling, which is defined as "the background knowledge about the nature of modelling, how it is conducted and why mathematics can be applied in real situations" (Brown and Stillman 2017, p. 357).

Third, aligning with social modelling competencies such as collaboration, argumentation and reporting (Galbraith et al. 2007; Kaiser 2007), but also to bolster the modelling activities, $15 \%$ of the course points could be earned through a group assessment, consisting of a complex modelling task, for which groups of four students had to develop a model and use it for solving a real-world problem, and they had to present their results to the whole group. They were given four weeks to carry out the work. The lecturer and their peers would then give a mark and feedback on different aspects of the work presented, such as mathematical strength of the model, evaluation of the model and presentation and group work skills. The final mark of this group assessment was calculated as $20 \%$ of the students' marks and $80 \%$ of the lecturer's mark. For further details on theoretical bases of the instructional design, see Hernandez-Martinez and Goos (2014).

The data for this paper come from semi-structured interviews at the end of the course. By interviewing students individually, we narrowed the issue "relevance according to whom?" down to "relevance according to the student" (and not according to a teacher or an employer). From all 40 students in the course, a random sample of 12 students was invited for an interview to evaluate the course and say something about it, whether positive or negative. Of these, 10 agreed. These 10 students were taking the course for the first time and all were between 20 and 22 years old. In this group of 10 , there was a slight overrepresentation of students with higher final marks for the course but still there were some students representative of lower marks. The spread of final marks of the interview participants was as follows: three A's (students 1, 2 and 3), three B's (students 4, 5 and 6), two C's (student 7 and 8), one E (student 9) and one F (failed) (student 10). However, it was not our aim to study the relation between relevance and attainment. The interviews were around one hour in length. The researcher first asked students to talk freely about their home and school backgrounds and experiences with the course, and in particular about the three key elements: the mathematical modelling tasks, the guest talk and the group assessment. In this way, the interviewer guided the issue "relevance of what?" towards the relevance of the three key elements. In most interviews, the students would answer to this guidance by including the issues "relevance to whom" and "relevance to what end". If this did not happen, the interviewer would follow up with specific questions related to the issue "relevance to whom" (e.g., Can you identify yourself doing the job of the guest speaker? or Did you and your peers find the presentation useful?) and to the issue "relevance to what end" (e.g., motives or motivation for dis/engaging with the activities, community rules from peers or the institution). The interviewer used the terms 'relevance' and 'usefulness' interchangeably, yet giving the students room to offer their personal perspectives.

The interviews were audio recorded, transcribed, and thereafter analysed in relation to the students' perceived relevance of the course, and of these three key elements of the course (modelling tasks, invited lecture, group assessment). We read the transcripts thoroughly and coded segments according to the theoretical issues of relevance identified before, that is: relevance according to the interviewed student, relevance of the key elements in the course, relevance to whom and relevance to what end. For the latter two issues we focused on motives (personal) vs. motivations (community), value (use or exchange), institutional rules, roles (division of labour) and tensions or contradictions (problematic relationships between aspects of the CHAT triangle). The aim was that this coding would provide an answer to the research question about how the students experienced the relevance of the different modelling activities of the course. In the next section, we present the results in subsections for each of the three key elements in the course. These key elements pertain to the issue "relevance of what". However, as relevance is a connection of different issues, the students' answers to the issue "relevance of what" could not be separated from the issues "relevance to whom" and "relevance to what end". To explicate these two latter issues as well, at the end of each subsection, we summarize the relevance of an activity according to the student, to whom, and to what end.

\section{Results}

All students, including the student who failed the course (student 10), acknowledged the value of mathematics for engineering. For instance, student 1 said:

Student 1: Maths and Engineering obviously... joint at the hips!

And student 10:

Int: To you, does maths have relevance in terms of advancing knowledge?

Student 10: Oh, $100 \%$, yeah, there is no way that the amount we know now would've been possible without maths. 
These students considered that mathematics was relevant to engineering, irrespective of whether they had aspirations to become professional engineers, and independently of the course. We now discuss how students ascribed relevance to each of the three key elements of the course mentioned above.

\subsection{The modelling tasks}

All but one student thought the modelling tasks were good and useful for their future professional lives. For example, student 8 said:

Student 8: I think as an engineer is definitely useful and it also gives you experience you could use in other areas like real world modelling not just here... science or other fields that may interest you even though you are not doing it and in this module, there was a lot of modelling and modelling cycle and stuff like that... good work.

The students valued the modelling tasks because these gave them practice of how they would use mathematics in their future jobs ("it gives you experience"). So, they imagined themselves working in future activity systems in which they will need mathematics. Some students, like student 8 , also mentioned that mathematics is relevant in areas in which they will not engage themselves ("even if you're not doing it"). However, student 4 took a different position. He found the modelling tasks interesting but not relevant given that he considered that this type of task was not part of the final exam, which was his target. He expressed it in the following way:

Student 4: The whole kind of... making maths more interesting was quite good but I don't think... I don't think it really helps with... 'cos most of what we do is based on the exam... at the moment my main target still are the exams, you know like, real world problems are good... and me and (other student) we do think about maths like in general life but really we are basing it in getting a good mark in the exam, we want to come out of university with like a good mark, a good grade, so this [modelling] didn't really focus on that, 'cos we look at past exam questions and this kind of questions weren't in there. (...)

This student did not once mention a future professional practice. He admits that his focus on exams is temporary ("at the moment my main target still are the exam"). His motivation for doing mathematics is to get the best possible grade in his degree; this goal-orientation remains within the educational system. We assert that this short-term goal also is an element of the relevance of this course: doing this course is relevant for this student with the goal of graduating with a good grade.

Student 10 provided an example of a student who enjoyed the modelling tasks while not being very good at mathematics. He explained that he had only an intermediate secondary school mathematics qualification, as opposed to most of his classmates who had an advanced level mathematics qualification. He described his situation in the following way:

Student 10: I really enjoy thinking how you can apply this to real world problems. (...) I can imagine being able to take this, apply it to a real world problem and solve it, that would be awesome, it's really exciting. (...) Me doing so badly hasn't changed my love for maths, I think it's awesome. (...) I did come to some of the lectures at the beginning but all I did was talk to my friend and I didn't engage at all and I didn't learn anything, really. (...) (In one lecture) I thought: "Oh this is too hard for me, I'm not going to do it'.

For this student, the modelling tasks were interesting in the sense that they had a value related to his "love for maths" and they were relevant because they had a value as being applicable to "real world problems" (in an unspecified activity system). And despite his perception of not being good at this type of mathematics, he maintains a perception of mathematics as being relevant. This is a tension that may produce disengagement. Also, this student indicated that the sessions with the modelling tasks seemed relevant to socialise with peers.

Thus, according to most students, the modelling tasks were perceived as relevant to them, with a goal-orientation (relevant to what end?) on their future professional lives, or more generally, on real world problems. Yet, we also see one student having a short-term goal: passing the exams and not finding the modelling activities as relevant for passing these.

\subsection{The invited talk}

In relation to the invited talk given by a guest from a wellknown British car and machine manufacturer, most students recognised that it was useful and relevant to their studies. For example, student 7 spoke as follows:

Student 7: I think it was a good idea, ehm... cos it was nice to see how you actually might use maths because obviously you spend all these time doing it... but it was not clear what parts are you going to use and... no, it was good having someone to come in because it sort of refocuses you, I think, to why you are doing it so I think that was useful.

And student 8 expressed it in the following way: 
Student 8: It was really helpful, I liked that (...) Int: Can you identify yourself doing that kind of work? Student 8: Possibly, it makes you realise it is relevant to what you could be doing, instead of being told... it's relevant for Materials, he comes in and says: "This is what I'm doing for my job" and with the graphs and everything, it is really clear that it's not just for show, really putting it to use.

Both students talk of a future beyond the educational activity system, in which they may encounter and use mathematics ("what parts are you going to use" and "what you could be doing"). As before, student 4 thought it was interesting but irrelevant to him and to his objective of obtaining a good mark. He said:

Student 4: A lot of people were saying, ehm... they didn't really understand why we were doing it, the various topics, whereas this guy coming in, he explained why you do them (...) It was interesting to see where would be used but I wasn't that bothered because even if I had paid attention to him I knew that wouldn't have affected my mark.

Also, there was another student who did not ascribe any value to the guest lecture. He knew that after graduating he would go into military training and get a job in the army. So, he could not see how the guest's job related to the kind of job he envisaged himself doing in the future. In CHAT terms, the imagined future activity system of the student was too different from the activity system of the guest speaker, making the activity 'solving problems within the enterprise'for which mathematics is a tool-being different from 'solving problems in the army' with the use of mathematics. The motive of the activity (i.e., using mathematics in industry) was very different to his motivation (i.e., getting a job in the army). He said:

Student 2: All of the stuff when they start talking about industry placement and "What you are going to do in industry", I just kind of switch off. (...)

Int: You had this guy from (industry name) presenting... how was that? Any interest?

Student 2: Umh, no, not at all (...) none of that... because he was talking about his job, wasn't he? And I thought: "I don't care about his job".

Student 5, who did a work placement year in the same manufacturing company as the guest speaker, did not think the guest's explanation of engineering work was accurate, and therefore it lacked any relevance for her. She explained:

Student 5: He kind of just like fobbed off what engineering was, and I was just sat here going... if I ask about this we're gonna be here another half hour because I have an opinion on this because I worked there for a year, so I'm not gonna say anything. But the way that he sort of described it just wasn't right.

We interpret this as a case of disagreement between the student and the guest speaker on elements within the activity system of the enterprise. As an intern, this student probably had a different role in the company than the guest (a fulltime employee), and therefore the division of labour was different for both. If they worked at different departments within the enterprise, the communities will have differed. This may have affected their knowledge of the company rules, the overall motives within the enterprise, their knowledge of mathematics used, and so forth. These differences then meant that the motive presented by the guest speaker did not correspond to the student's motive for the professional activity and therefore she did not ascribe any value to the lecture by the guest.

Thus, according to most students, the guest talk was perceived as relevant to them, with a goal-orientation (relevant to what end?) on their future professional lives. Yet, we also see a student expecting to enter a different profession, a student who has a different perspective on the work done by the guest speaker, and again, we see the student with the short-term goal of passing the exams: for these students the guest talk was irrelevant (and even irritating).

\subsection{The group assessment}

In relation to the group assessment, most of the interviewed students thought it was useful, in particular being able to work as a group and explaining to others in a presentation. Most of them related this to the development of mathematical understanding and skills that will be valued in the world of work. For instance, student 8 said:

Student 8: Specially when you can work with the people you choose to, I mean, before all the group coursework started, sometimes you have to talk to others you wouldn't really want to, and that's what you'd be doing... the rest of your life, I think. So it helps in that way. And just group work in general. Even when you are working with people you like, it still helps 'cos they can give insights into maths you don't know, and change the way you think.

Only students 4 and 7 thought the group assessment was good in some respects but not in others. For example, student 7 said:

Student 7: It was good, I mean everyone pulled their way which was sort of... the thing you worry most about the group presentations. (...) We sort of allocated people to each question. (...) We find that one sort of quite difficult because obviously there's not sort of... a model that's ever right. 
Int: And presenting?

Student 7: Not really, cos I mean last semester we did a 20 min presentation to people in industry that came in and that was lot of preparation that went in, it was a lot more time and it was a lot more difficult, ehm... I think it was a lot more useful than sort of 5, $10 \mathrm{~min}$.

As can be seen, this student did not ascribe value to the presentation because in her view she could acquire this type of skill in a better way in a course where more preparation was needed, the degree of difficulty was higher and the rewards could be greater (i.e., potential employers judging the presentation). To her, the presentation as part of the mathematics course had value only as part of the educational activity system. Unlike other students who saw this within the perspective of future jobs ("that's what you'd be doing... the rest of your life"), to her this could not be transferred into the professional practice in any worthy way.

Thus, according to most students, the group assessment was perceived as relevant to them, with a goal-orientation (relevant to what end?) on their future professional lives. Yet, we also see a student giving a critique, comparing the group presentation to another experience where the demands were much higher: for this student the group assessment did not have that much relevance.

\section{Discussion, conclusions and recommendations}

Our research started from the frequently asked question "Why do I have to learn this?" in mathematics classrooms, asking for the relevance of doing mathematics. Based on the recommendation that the relevance of mathematics can be mediated through mathematical modelling activities (Blum 2015; Stillman et al. 2013b), we translated this question into an object of study: students' experience of the relevance of mathematical modelling activities. Our research was guided by the question: How do students experience relevance of mathematical modelling activities? To find answers, we found in Nyabanyaba (1999), Ernest (2004) and Jablonka (2007) that relevance is a connection among four issues (relevance of what? to whom? according to whom? and to what end?). Thereafter, we framed relevance within a socio-cultural theory and studied elements of relevance empirically, by analysing students' comments on key elements pertaining to mathematical modelling within a mathematics course for engineers.

We found that most students found the modelling activities relevant. Incidentally, we did not observe a strong relationship between the students' perception of relevance and their attainment: students that achieved high marks in the course (e.g., students 2 and 4) found some aspects of the modelling activities not so relevant while others that did not do so well found some of these activities highly relevant (e.g., students 8 and 10). Therefore, we found relevance to be a multifaceted concept. It connects people, their perspectives and their activities and these connections are strongly shaped by the socio-cultural environment.

The four issues that relate to relevance (relevance of what? to whom? according to whom? and to what end?) cannot be described unambiguously. For example, the first question "relevance of what?" points at a complex object. One can mention the relevance of mathematics (for solving real life solutions), which differs from the relevance of learning mathematics (for obtaining knowledge and skills to do mathematics), which yet again differs from the relevance of mathematical modelling activities (for learning to use mathematics for solving real life problems), and so forth. We assert that relevance can be connected to many objects. To limit the study described in this article, we focused on the relevance of mathematical modelling activities in an undergraduate mathematics course for university students in engineering. We designed different mathematical modelling activities (modelling tasks, a guest lecture, a group assessment), aligning with descriptions of cognitive modelling competences as described in modelling cycles (e.g., Galbraith et al. 2007; Kaiser 2007), meta-knowledge (Brown and Stillman 2017) and social modelling competencies (collaboration, argumentation and reporting) (Galbraith et al. 2007; Kaiser 2007). We found differences in students' judgements about the relevance of these activities. So, even if the modelling activities were tailored to students' future professions, and considering the small grain size used for studying the relevance of these activities, students' judgements still varied. This means that a wider perspective on the relevance of mathematics at large will yield a more complex picture, in particular as the subject of mathematics also may contain topics that are irrelevant to many students. We therefore recommend more studies on what mathematics is needed in future jobs, such as those carried out by Van der Wal et al. (2017) or Wake (2013), and studies on how seemingly irrelevant mathematical topics could be made more relevant, considering Alsina's (2007) warning: "Crossing rivers, climbing castles, covering chessboards with tetraminos-who does these things today? Useless mathematics cannot become useful even if it is presented in a fun way" (p. 42).

The second issue, "relevance to whom?" clarifies that relevance is connected to a person (the subject of the activity). In our study we focused on engineering students at a university, to whom the mathematical modelling activities were tailored. Engineering is an area that is strongly connected to the use of mathematical models, and university students will have a better orientation on their professional future than younger students, so most students recognized the modelling 
activities as being relevant to them. Yet, to some students, some of the activities lacked relevance, for example because they did not plan to become engineers (but, e.g., to join the army) or because the modelling activities did not prepare them on the short term goal of passing the exams. Thus, to tailor activities to a broad target group still requires teachers to convey that these activities can also be relevant to other groups (engineering skills are also required in the army). Additionally, the traditional time-restricted written tests that are common in mathematics education need adaptation, as these cause tensions between students' short-term and long term goals. This is a direct consequence of the position that mathematics occupies in the structure of modern societies, that is, mathematics has a value that has on the one hand to do with knowledge and competences-its use-value-and on the other hand to do with selection-its exchange-value (Jablonka 2007; Pais 2013).

The third issue, "relevance according to whom?" clarifies that relevance is a subjective judgement that will depend on the person judging. In our study, we focused on the students, but one can also study the viewpoint of an employer, a parent or a teacher. We saw that the judgement by one person did not always yield a clear cut yes/no-answer. Although most students experienced the mathematical modelling activities in the course as relevant, there were also nuances. For example student 7 considered group presentations on the modelling solutions in general as relevant, but she wished these to be more demanding or to carry a greater value.

The last issue, "relevance to what end?" clarifies the goal-directedness of relevance. Relevance must have purpose. For this issue we benefitted from framing relevance in an activity system for the social environment in which students learn mathematics. Within such activity systems the goal-directedness relates to motives and motivations. In the modelling course for engineers, we saw that a majority of the students had career plans and imagined themselves working in professional practices. Thus, they found motivation beyond the educational system and the modelling tasks clearly supported this. However, we also saw a student, who reasoned entirely within the educational system wanting to 'pass the exam'. While the institution's motive was to prepare the students for their future professions in which they would need to use mathematical models, this student judged that the modelling activities had little value for him and therefore were irrelevant. In this case, there was clearly a tension between motives and motivation. In a similar vein, there will be tensions when a student wants to 'pass the exam', but the teacher insists that students should engage in a deep way with the material because conceptual learning will yield more retention than procedural learning (Hiebert 1986). Such students will judge the activity aiming at conceptual learning as irrelevant. Bringing relevance to students whose motivation narrows down to 'passing the exam' is a challenge for educational institutions that maybe need to reconsider some of their rules (e.g., high-stakes final examinations), tools (e.g., design of innovative assessment practices that focus on conceptual understanding rather than memorisation) or division of labour (e.g., considering students as partners in their education).

In our empirical study, we observed other tensions between student's motivation and the institution's motives. This happened when there was a lecture by a guest speaker from a commercial enterprise. For most students it worked well, and the guest lecturer brought the future world of work into the classroom. However, one student imagined himself working in a different future environment (in the army), and another student had been in a work placement in the enterprise from which the guest speaker came, and disagreed about how the guest lecturer spoke of the use of mathematics there. This showed that motives and motivation do not always align, and that having guest lectures may explain the relevance of mathematics, but such a lecture can also demotivate some.

In our study, we also observed other characteristics of 'doing mathematics' that add relevance. For example, some students enjoyed being sociable in the classroom, working in groups, and presenting their results to the whole class. To make students responsible for the work being done, and to develop equitable relations (Boaler 2008), this might be judged by students to have a social value. One student related such activities also to a future practice, saying: "you have to talk to others you wouldn't really want to, and that's what you'd be doing... the rest of your life, I think". Thus, the institution's motive to include soft skills in the course aligned with a student's motivation to engage in such activities, making these relevant to him.

The activity system in Fig. 2 exemplifies elements that can make 'doing mathematics' relevant. Some elements from students' future professional practices could be used in mathematical modelling tasks. If textbooks and teachers use such appealing contexts, they might 'add' relevance to classroom activities. Future professional practices can be brought into the classroom by guest lectures, but also through excursions in which students leave the educational institute and visit an enterprise or university where they simulate mathematical modelling research through complex tasks on which students work for a long stretch of time, such as in the Mathematical Modelling Weeks (Kaiser et al. 2013) or the excursion Railway Timetable Dynamics (Vos 2015). These activities are closer to actually experiencing a professional practice, although with some restrictions (e.g., students are not subjected to the rules of employment but they can experience certain authentic tools). By making more concrete those elements of a professional practice that could only be imagined before, more students will be able to see the relevance of 


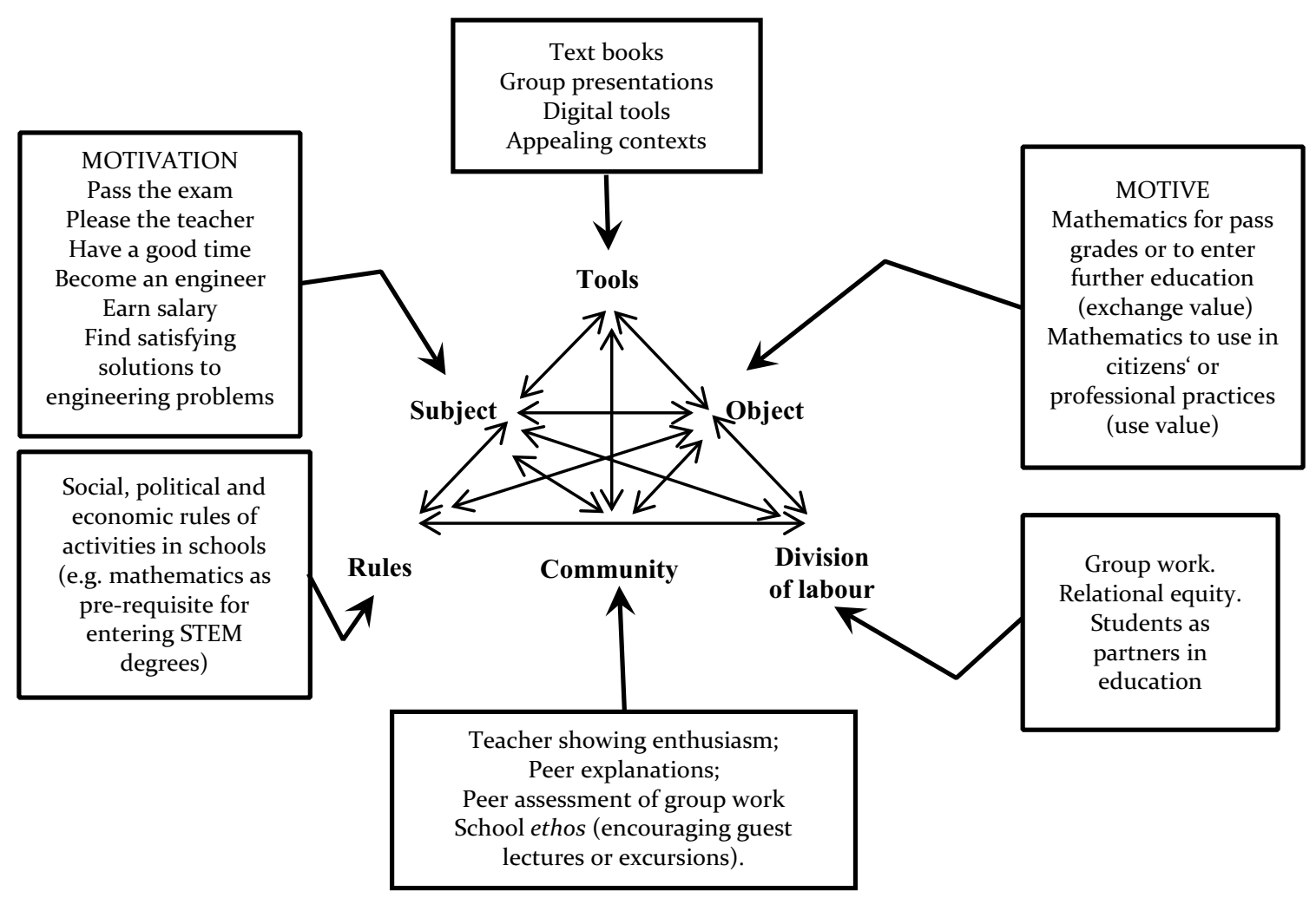

Fig. 2 Characteristics of "doing mathematics" in engineering education, and elements of relevance

mathematics to their future lives. Such activities need to be facilitated within the educational system (school rules, finances, ethos), which explains why students' perceptions of relevance depend on the schools they attend (Sealey and Noyes 2010). In fact, there are many ways in which mathematical modelling activities can make students experience relevance in mathematics classrooms so they no longer need to ask "Why do I have to learn this?"

Acknowledgements We would like to thank Antony Edwards and the anonymous reviewers for their advice.

Open Access This article is distributed under the terms of the Creative Commons Attribution 4.0 International License (http://creativecommons.org/licenses/by/4.0/), which permits unrestricted use, distribution, and reproduction in any medium, provided you give appropriate credit to the original author(s) and the source, provide a link to the Creative Commons license, and indicate if changes were made.

\section{References}

Alpers, B. A., Demlova, M., Fant, C.-H., Gustafsson, T., Lawson, D., Mustoe, L., Olsen-Lehtonen, B., Robinson, C. L., \& Velichova, D. (2013). A framework for mathematics curricula in engineering education: A report of the Mathematics Working Group. Brussels: European Society for Engineering Education (SEFI).
Alsina, C. (2007). Less chalk, less words, less symbols... more objects, more context, more actions. In W. Blum, P. L. Galbraith, H.-W. Henn \& M. Niss (Eds.), Modelling and applications in mathematics education (pp. 35-44). New York: Springer.

Black, L., Williams, J., Hernandez-Martinez, P., Davis, P., Pampaka, M., \& Wake, G. (2010). Developing a 'leading identity': The relationship between students' mathematical identities and their career and higher education aspirations. Educational Studies in Mathematics, 73(1), 55-72.

Blum, W. (2015). Quality teaching of mathematical modelling: What do we know, what can we do? In S. J. Cho (Ed.), Proceedings of the 12th international congress on mathematical education (pp. 73-96). New York: Springer.

Boaler, J. (2008). Promoting 'relational equity' and high mathematics achievement through an innovative mixed ability approach. British Educational Research Journal, 34(2), 167-194.

Bonotto, C. (2010). Realistic mathematical modeling and problem posing. In R. Lesh, P. L. Galbraith, C. R. Haines \& A. Hurford (Eds.), Modeling students' mathematical modeling competencies (pp. 399-408). New York: Springer.

Brown, J. P., \& Stillman, G. A. (2017). Developing the roots of modelling conceptions: 'Mathematical modelling is the life of the world'. International Journal of Mathematical Education in Science and Technology, 48(3), 353-373.

Brown, M., Brown, P., \& Bibby, T. (2008). "I would rather die": Reasons given by 16-year-olds for not continuing their study of mathematics. Research in Mathematics Education, 10(1), 3-8.

Cardella, M. E. (2010). Mathematical modeling in engineering design projects. In R. Lesh, P. L. Galbraith, C. R. Haines \& A. Hurford (Eds.), Modeling students' mathematical modeling competencies (pp. 87-98). New York: Springer.

Cockroft, W. H. (1982). Mathematics counts. London: HMSO. 
Engeström, Y. (1987). Learning by expanding. Cambridge: Cambridge University Press.

Engeström, Y. (1999). Innovative learning in work teams: Analysing cycles of knowledge creation in practice. In Y. Engeström, R. Miettinen \& R.-L. Punamäki (Eds.), Perspectives on Activity Theory (pp. 377-406). Cambridge: Cambridge University Press.

Ernest, P. (2004). Relevance versus utility: Some ideas on what it means to know mathematics. In B. Clarke, D. M. Clarke, G. Emanuelsson, B. Johansson, D. V. Lambdin, F. K. Lester, A. Wallby \& K. Wallby (Eds.), International perspectives on learning and teaching mathematics (pp. 313-327). Göteborg: National Center for Mathematics Education.

Ernest, P. (2005). Platform: Why teach mathematics? Mathematics in School, 34(1), 28-29.

Galbraith, P., Stillman, G., Brown, J., \& Edwards, I. (2007). Facilitating middle secondary modelling competencies. In C. Haines, P. Galbraith, W. Blum \& S. Khan (Eds.), Mathematical modelling: Education, engineering and economics (pp. 130-140). Chichester: Horwood Publishing.

Hernandez-Martinez, P., \& Goos, M. (2014). Mathematics at university: Practices, values and participation. In G. Adams (Ed.), Proceedings of the British society for research into learning mathematics, 34(2). Southampton: BSRLM.

Heymann, H. W. (2003). Why teach mathematics? A focus on general education (Vol. 33). Dordrecht: Kluwer Academic.

Hiebert, J. (Ed.). (1986). Conceptual and procedural knowledge: The case of mathematics. Hillsdale: Lawrence Erlbaum Associates.

Jablonka, E. (2007). The relevance of modelling and applications: Relevant to whom and for what purpose? In W. Blum, P. L. Galbraith, H.-W. Henn, \& M. Niss (Eds.), Modelling and applications in mathematics education (pp. 193-200). New York: Springer.

Julie, C., \& Holtman, L. (2008). The Relevance of School Mathematics Education (ROSME). In L. Holtman, C. Julie, Ø. Mikalsen, D. Mtetwa \& M. Ogunniyi (Eds.), Some developments in research in science and mathematics in Sub-Saharan Africa, Access, relevance, learning, curriculum research (pp. 379-405). Somerset West: African Minds.

Julie, C., \& Mudaly, V. (2007). Mathematical modelling of social issues in school mathematics in South Africa. In W. Blum, P. L. Galbraith, H.-W. Henn \& M. Niss (Eds.), Modelling and applications in mathematics education (pp. 503-510). New York: Springer.

Kaiser, G. (2007). Modelling and modelling competencies in school. In C. Haines, P. Galbraith, W. Blum \& S. Khan (Eds.), Mathematical modelling: Education, engineering and economics (pp. 110-119). Chichester: Horwood Publishing.

Kaiser, G. (2014). Mathematical modelling and applications in education. In S. Lerman (Ed.), Encyclopedia of mathematics education (pp. 396-404). Dordrecht: Springer.

Kaiser, G., Bracke, M., Göttlich, S., \& Kaland, C. (2013). Authentic complex modelling problems in mathematics education. In A. Damlamian, J. F. Rodrigues \& R. Sträßer (Eds.), Educational interfaces between mathematics and industry (pp. 287-297). New York: Springer.

Kaiser, G., Schwarz, B., \& Buchholtz, N. (2011). Authentic modelling problems in mathematics education. In G. Kaiser, G. Stillman, W. Blum \& R. Borromeo Ferri (Eds.), Trends in teaching and learning of mathematical modelling (pp. 591-601). Dordrecht: Springer.

Kember, D., Ho, A., \& Hong, C. (2008). The importance of establishing relevance in motivating student learning. Active Learning in Higher Education, 9(3), 249-263.

Liebendörfer, M., \& Schukajlow, S. (2016). Interest development during the first year at university: Do mathematical beliefs predict interest in mathematics? ZDM Mathematics Education, pp. 1-12.

Loch, B., \& Lamborn, J. (2016). How to make mathematics relevant to first-year engineering students: Perceptions of students on resources produced by students. International Journal of Mathematical Education in Science and Technology, 47(1), 29-44.

Maaß, K. (2006). What are modelling competencies? ZDM-The International Journal on Mathematics Education, 38(2), 113-142.

Maaß, K. (2010). Modeling in class and the development of beliefs about the usefulness of mathematics. In R. Lesh, P. L. Galbraith, C. R. Haines, \& A. Hurford (Eds.), Modeling students' mathematical modeling competencies (pp. 409-420). New York: Springer.

Matthews, A., \& Pepper, D. (2005). Evaluation of participation in A level mathematics: Interim report. London: Qualifications and Curriculum Agency.

McLeod, D. B. (1992). Research on affect in mathematics education: A reconceptualization. In D. Grouws (Ed.), Handbook of research on mathematics teaching and learning (pp. 575-596). New York: Macmillan.

Newby, T. J. (1991). Classroom motivation: Strategies of first-year teachers. Journal of Educational Psychology, 83, 195-200.

Niss, M. (1994). Mathematics in society. In R. Biehler, R. Scholz, R. Straesser \& B. Winkelmann (Eds.), The didactics of mathematics as a scientific discipline (pp. 367-378). Dordrecht: Kluwer Academic Publishers.

Nyabanyaba, T. (1999). Whither relevance? Mathematics teachers' discussion of the use of 'real-life' contexts in school mathematics. For the Learning of Mathematics, 19(3), 10-14.

Onion, A. (2004). What use is maths to me? A report on the outcomes from student focus groups. Teaching Mathematics and its Applications, 23(4), 189-194.

Pais, A. (2013). An ideology critique of the use-value of mathematics. Educational Studies in Mathematics, 84(1), 15-34.

Rellensmann, J., \& Schukajlow, S. (2016). Does students' interest in a mathematical problem depend on the problem's connection to reality? An analysis of students' interest and pre-service teachers' judgments of students' interest in problems with and without a connection to reality. ZDM, 49(3), 367-378.

Roszkowski, M. J., \& Soven, M. (2010). Did you learn something useful today? An analysis of how perceived utility relates to perceived learning and their predictiveness of satisfaction with training. Performance Improvement Quarterly, 23(2), 71-91.

Schukajlow, S., Leiss, D., Pekrun, R., Blum, W., Müller, M., \& Messner, R. (2012). Teaching methods for modelling problems and students' task-specific enjoyment, value, interest and self-efficacy expectations. Educational Studies in Mathematics, 79(2), 215-237.

Sealey, P., \& Noyes, A. (2010). On the relevance of the mathematics curriculum to young people. The Curriculum Journal, 21(3), 239-253.

Stillman, G. A., Brown, J. P., \& Galbraith, P. (2013a). Challenges in modelling challenges: Intents and purposes. In G. A. Stillman, G. Kaiser, W. Blum \& J. P. Brown (Eds.), Teaching mathematical modelling: Connecting to research and practice (pp. 217-227). Dordrecht: Springer.

Stillman, G. A., Kaiser, G., Blum, W., \& Brown, J. P. (2013b). Mathematical modelling: Connecting to teaching and research practices-The impact of globalisation. In G. A. Stillman, G. Kaiser, W. Blum, \& J. P. Brown (Eds.), Teaching mathematical modelling: Connecting to research and practice (pp. 1-24). Dordrecht: Springer.

Van der Wal, N. J., Bakker, A., \& Drijvers, P. (2017). Which technomathematical literacies are essential for future engineers? International Journal of Science and Mathematics Education, 15(1), 87-104.

Vos, P. (2015). Authenticity in extra-curricular mathematics activities; Researching authenticity as a social construct. In G. Stillman, W. Blum \& M. S. Biembengut (Eds.), Mathematical modelling in education research and practice: Cultural, social and cognitive influences (pp. 105-114). New York: Springer. 
Wake, G. (2015). Preparing for workplace numeracy: A modelling perspective. ZDM, 47(4), 675-689.

Wedege, T. (2007). Needs versus demands: Some ideas on what it means to know mathematics in society. In B. Sriraman \& S. Goodchild (Eds.), Relatively and philosophically earnest: Festschrift in honor of Paul Ernest's 65th Birthday (pp. 221-234). Charlotte: Information Age Publishing.
Wells, G. (2011). Motive and motivation in learning to teach. In D. McInerney, R. Walker \& G. Liem (Eds.), Sociocultural theories of learning and motivation: Looking back, looking forward (pp. 87-107). Charlotte, NC: Information Age Publishing.

Zempke, R., \& Zempke, S. (1981). 30 things we know for sure about adult learning. Training, 45-49. 